\title{
1. An Overview of the 2007 Election in Papua New Guinea
}

\author{
Andrew S. Trawen MBE, Chief Electoral Commissioner
}

When I was invited to provide an introductory overview of the 2007 general election from the perspective of the Papua New Guinea Electoral Commission (PNGEC) I was pleased to accept, given the past working relationship between the National Research Institute, The Australian National University and the PNGEC. What I present is a brief analysis from the PNGEC's viewpoint, outlining the challenges and presenting a road map for the PNGEC to follow as it strives to achieve greater efficiency in electoral administration and conduct.

\section{The election schedule}

Let me begin with the important dates for the national election. They are:

- $\quad$ issue of writs, 4 May 2007

- close of nominations, 10 May 2007

- commencement of polling, 30 June 2007

- completion of polling, 10 July 2007

- return of writs, 30 July 2007.

Polling in parts of the country was slightly behind schedule due to prevailing circumstances beyond the control of the PNGEC, mainly to do with weather conditions, sudden changes in air transport schedules during the polling period, and numerous court injunctions. This was mainly in the Highlands Region and parts of the Southern and Momase Regions. Section 82A of the Organic Law on National and Local-level Government Elections gives flexibility to the PNGEC to determine the timeframe for the elections and this worked very well in the 2007 election.

\section{Election statistics}

A total of 2759 candidates nominated for the 109 seats; just over half of these (1478) contested as independents. There were 2658 male candidates and 103 female candidates. 
The electoral roll had 3,938,839 registered voters. The highest number of candidates in any electorate was 69, the lowest 7 . There were 34 registered political parties.

Over 9000 polling places were established, with 4550 polling teams and approximately 27,500 polling officials. The number of ballot papers that were printed was 9,096,100, of which 8,519,200 were distributed.

\section{The voting system}

Papua New Guinea used the limited preferential voting (LPV) system for the first time in a post-independence general election, shifting away from the old first-past-the-post system. Candidates and their supporters cooperated during the election, unlike the past where violence was the norm. The new voting system increased the percentage of popular support for members of parliament to over 50 percent of the electorate. Early indications suggest the LPV system is user-friendly. It is my firm view that the new LPV system was a success.

My estimate of formal votes cast is over 85 percent, and I think that with better understanding of the system the percentage of informal votes will decrease. I believe we witnessed a high level of support for the LPV system.

\section{The electoral roll}

A complete review of the 2002 general election revealed that the electoral roll used was heavily inflated and absolutely corrupted.

I made the decision in 2005, after being appointed commissioner, to completely discard the 2002 electoral roll. The mammoth task of creating the new 2007 roll began immediately and enumerators across the country went from door to door. In a number of instances, they were not well received by households. This, as well as blatant refusal to enrol by some eligible voters, resulted in names not being on the 2007 electoral roll.

By 18 June 2007, the PNGEC had processed all completed eligible voter registration forms. Upon completion, the 2007 electoral roll registered a total of 3,938,839 voters throughout the country, compared to about five million in 2002. The truth is that in Papua New Guinea it is difficult to remove names from the electoral roll, and it is also hard to counter the culture of getting as many names as possible on the roll. 
The electoral rolls were for the first time done at local-level government (LLG) ward level so they could be easily managed. Although there were problems in accommodating voters from other wards or LLGs voting in the same electorate, the PNGEC was able to control the movement of people to prevent voting twice or three times in the same electorate.

\section{Logistics}

Papua New Guinea is sparsely populated, with limited or poor road and sea transport infrastructure. This meant that delivery of important election materials to polling locations within tight time frames was extremely difficult. The majority of critical supplies, such as ballot papers, electoral rolls, candidate posters, voting forms, labels and seals were dispatched by air transport. Large items were sent by sea freight where time permitted. In 2007, certain transport companies slowed down the election process by not delivering critical supplies to destinations on time.

\section{Awareness and education}

A voter awareness campaign was slow to start but picked up momentum as elections drew near, though there were complaints of insufficient awareness and education. Comprehensive awareness education on the voting process, using radio, television and the press, did not reach certain more remote parts of the country simply because the services were not available. It seems the PNGEC will always struggle in this area because of poor communications infrastructure.

The Australian Government-funded Electoral Support Program assisted considerably in the awareness process, through the use of civil society organizations.

\section{Security}

Security is always a major concern, especially in the Highlands Region. Polling was conducted over a shorter period in the Highlands instead of the full 11 days of polling. This was done to allow security forces to focus their limited resources on 'hot spots'. The strategy worked well and general feedback suggests that security was generally considered to have been a success. 


\section{Finances}

A new financial management system was introduced by PNGEC for the control, monitoring and expending of funds allocated by the national government.

PNGEC submitted a financial estimate of K130 million to Treasury Department for election administration. However parliament appropriated a total of K130 million for the election, of which security consumed K50 million, leaving only K80 million for actual election administration. The amount was insufficient, and the PNGEC incurred further costs after the July election. An additional K15 million was requested in the government's supplementary budget towards the end of 2007. This was appropriated and the Commission managed to settle most of its outstanding debts. However, claims were still coming in from the provinces early in 2008 and there is a possibility of additional costs of up to K3 million.

\section{Election petitions}

The intensity of court petitions after the return of writs for a general election is a recurring issue of concern in Papua New Guinea. The number of election disputes reflects on the degree of success or failure of any general election. Fifty-five petitions were filed with the Court of Disputed Returns in 2007. This compares with 98 cases filed in the aftermath of the 2002 elections.

This is a significant decline, which may be attributed to the new LPV system and the stringent imposition of court rules that determine the validity and merit of cases filed by losing candidates.

\section{Challenges}

I have given you a brief overview of the 2007 general election in Papua New Guinea. As a young developing nation in this part of the world, we are still in aggressive pursuit of that perfect election model which we ourselves believe is the right one. We are open to critics and will take the opportunity to receive and digest comments.

We went through several reviews immediately after the 2007 election and we know our strengths and weaknesses. Our immediate challenge is to address issues identified in the various election review workshops as 'lessons learnt' and to incorporate them into our electoral management system for practical application. 
Challenges facing the PNGEC come from all facets of election administration and conduct. There are problems in voting, electoral rolls, counting and scrutiny, finance, transportation, communications, security, training and recruitment, and awareness and education.

There have always been problems with elections in Papua New Guinea, since the first general election in 1977. The general election in 2007 took a more positive twist with the introduction of the 'whole-of-government' approach. The national election steering committee known as the Inter-departmental Electoral Committee (IDEC) was formed. Its primary role was to coordinate all state agencies to effectively assist the PNGEC conduct the general elections. The Chairman of IDEC was the registrar of political parties, Mr Paul Bengo, a veteran civil servant and one of Papua New Guinea's senior statesmen. The setting up of IDEC was a step in the right direction and I am proud to say that much has been achieved in 2007. Our focus now is to strengthen and legitimize IDEC to enable it to become more effective in its role.

Primary tasks awaiting the PNGEC's attention are to:

- continue to improve the integrity of the electoral roll and foster the "wholeof-government' approach to elections

- increase LPV awareness

- improve on electoral procedures in relation to administration and conduct of elections

- review the Organic Law on National and Local-level Government Elections and its Regulations. 